\title{
APPROACHES TO RESULTS-BASED FUNDING IN TERTIARY EDUCATION Identifying Finance Reform Options for Chile
}

\author{
World Bank \\ Latin American and Caribbean Region \\ Department for Human Development
}

Kristian Thorn, Lauritz Holm-Nielsen, and Jette Samuel Jeppesen ${ }^{1}$

\begin{abstract}
Unrealized potential exists for increasing accountability and transparency in Chilean tertiary education by allocating resources based on achieved results rather than historical precedence and political negotiation. Against this background, the paper profiles approaches to results-based funding of tertiary education to identify efficacious finance reform options for Chile. International experience shows that financing by results is not a ready-made concept, but a broad label that offers a menu of design options. To decipher results-based funding, the paper covers all phases in designing and implementing a results-based funding system and highlights strengths and weaknesses of concepts such as taximeter funding, performance contracts and formula-based allocations.
\end{abstract}

\section{World Bank Policy Research Working Paper 3436, October 2004}

The Policy Research Working Paper Series disseminates the findings of work in progress to encourage the exchange of ideas about development issues. An objective of the series is to get the findings out quickly, even if the presentations are less than fully polished. The papers carry the names of the authors and should be cited accordingly. The findings, interpretations, and conclusions expressed in this paper are entirely those of the authors. They do not necessarily represent the view of the World Bank, its Executive Directors, or the countries they represent. Policy Research Working Papers are available online at http://econ.worldbank.org.

${ }^{1}$ The authors wish to thank the following persons for their comments and suggestions: José Joaquín Brunner, Director of Education Program, Fundación Chile; Joseph Burke, Director of Higher Education, The Nelson A. Rockefeller Institute of Government; Eduardo Velez Bustillo, Education Sector Manager, Latin America and the Caribbean Region, World Bank; Eric Canton, Researcher, The Netherlands Bureau for Economic Policy Analysis; Jesko S. Hentschel, Country Sector Leader in Human Development for Argentina, Chile, Paraguay, and Uruguay, World Bank; Ricardo Reich, Director, Chile: Higher Education Quality Improvement Program (MECESUP), Ministry of Education; and Salvatore Schiavo-Campo, Senior Advisor for Governance and Public Management, World Bank. 


\section{ACRONYMS}

AFD

AFI

CFT

$\mathrm{CRUCH}$

DIVESUP

FDI

IP

MECESUP

MINEDUC

PAA
Direct public support (Aporte Fiscal Directo)

Indirect public support (Aporte Fiscal Indirecto)

Technical Training Centers (Centro de Formación Técnica)

Council of Rectors (Consejo de Rectores)

Higher Education Division in the Ministry of Education (División de Educación Superior)

Institutional Development Fund (Fondo de Desarrollo Institucional)

Professional institutes (Institutos Profesionales)

Quality and Equity Improvement in Higher Education (Mejoramiento de la Calidad y la Equidad en la Educación Superior)

Ministry of Education (Ministerio de Educación)

Academic Aptitude Test (Prueba de Aptitud Académica) 


\section{TABLE OF CONTENTS}

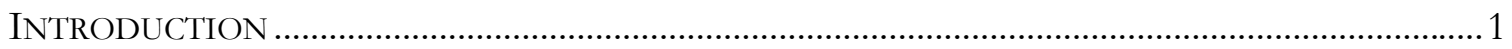

1. CHILEAN PUBLIC FINANCING SYSTEM OF TERTIARY EDUCATION ........................................... 2

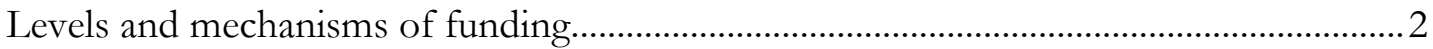

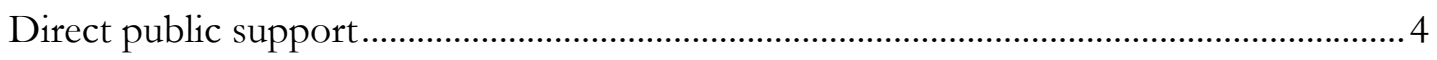

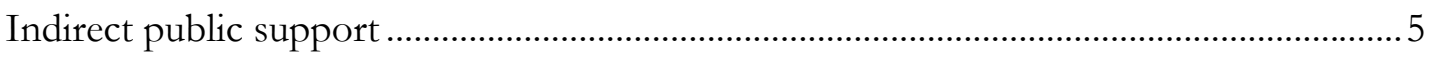

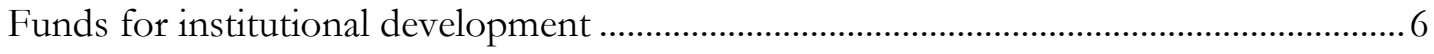

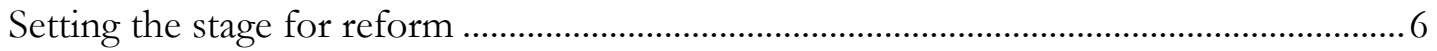

2. FUNDING HIGHER EDUCATION INSTITUTIONS BASED ON RESULTS ........................................ 6

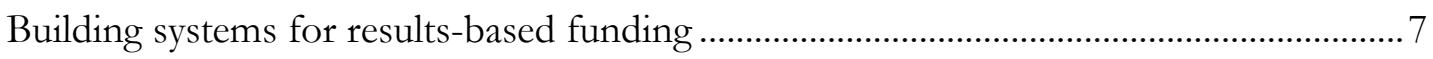

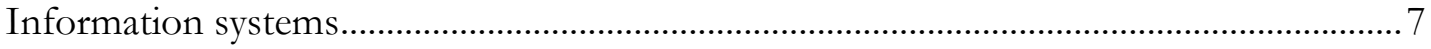

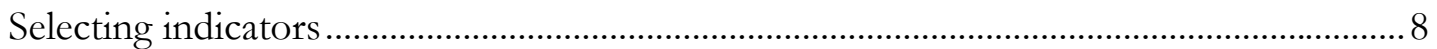

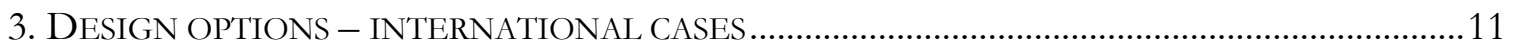

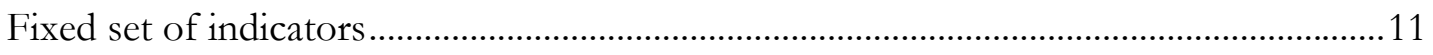

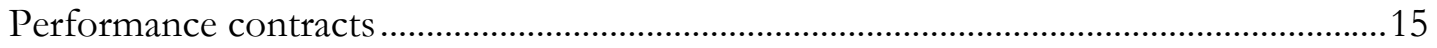

4. REWARDING INSTITUTIONS BASED ON PERFORMANCE ….........................................................16

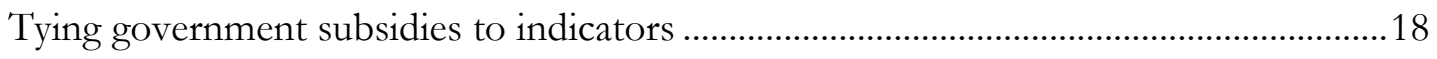

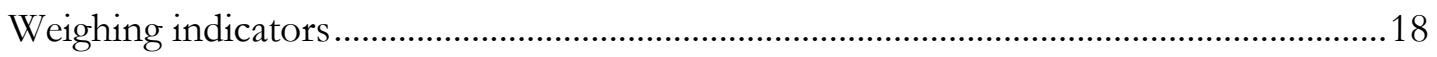

Levels of results-based funding ......................................................................................... 18

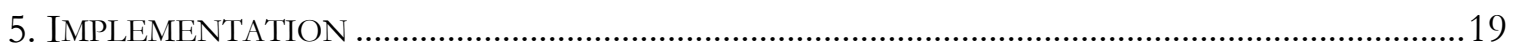

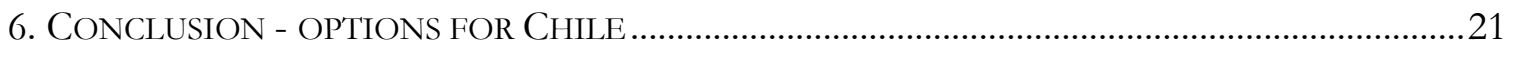

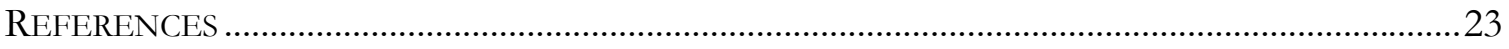




\section{INTRODUCTION}

Chile is rapidly moving to a mass tertiary education system. Over the past decade enrollment in Chilean higher education expanded significantly from about 250,000 students in 1990 to more than 500,000 in 2003. Nearly all of the expansion was financed by private sources, reflecting a policy of cost-recovery and growth in private provision of tertiary education. Today, Chile is among the countries in Latin America that allocate the least public funding to higher education relative to GDP. Yet, due to sizable private spending, Chile features the highest share of GDP allocated to higher education in the region.

Significant private contributions to the financing of tertiary education provide an opportunity for the Chilean government to strategically reorient resources to core public sector responsibilities. By prioritizing public resources and focusing on value for money, Chile may address pressing sector issues such as inequities, insufficient supply of doctoral graduates and lack of coherence and flexibility between tertiary learning settings.

The Government of Chile has already begun a process of reprioritizing public resources by significantly scaling up support for student loan programs. In addition, about 7 percent of public financing for tertiary education is tied to a best-student formula and 5 percent of the base funding for the 25 traditional universities is allocated according to performance criteria. Nonetheless, unrealized potential remains for tying funding to desired educational outcomes. Almost half of all public subsidies for tertiary education are allocated based on historical precedence and there is no system for collecting reliable, standardized information on the performance of tertiary institutions.

This paper profiles international experiences and discusses strengths and weaknesses in approaches to results-based funding of tertiary education in order to identify finance reform options for Chile. The structure of the paper reflects the phases involved in designing a results-based funding system. The first section briefly describes the Chilean public financing system of tertiary education. Section two discusses the need for establishing data collection structures and identifies steps involved in selecting performance criteria. Section three outlines strengths and weaknesses of design options drawing on examples of results-based funding systems in Africa, Europe, Latin America and North America. With a complete evaluation model in place, section four reflects on how resources can be tied to selected indicators. Section five discusses implementation issues when introducing a results-based funding system. Finally, section six outlines possible finance reform options for Chilean tertiary education in light of international experiences. 


\section{CHILEAN PUBLIC FINANCING SYSTEM OF TERTIARY EDUCATION}

The Chilean tertiary education system was changed profoundly during the 1980s following the most radical reforms to university education ever attempted in the region. The reforms aimed at improving efficiency by deregulating the sector and stimulating private provision. Moreover, the reforms sought to alleviate the finance burden of the state by charging tuition to students and encouraging higher education institutions to diversify their funding sources. As a result, Chile today features one of the strongest markets for tertiary education in the region.

The Chilean tertiary education system is comprised by three types of institutions: Universities offer undergraduate first-degree and postgraduate programs. They are the only institutions authorized to award bachelor, master and doctoral academic degrees in Chile. Moreover, universities are the only institutions authorized to award professional certificates in 17 professional fields (engineering, medicine, law, psychology, architecture, etc.). Professional institutes (IP) deliver four-year programs and are authorized to award professional certificates in any field, excluding the 17 fields that are the prerogative of universities. Technical Training Centers (CTF) offer two-year technical vocational programs which lead to a Higher Technical Level Certificate.

Table 1. The Chilean Tertiary Educational System, 2002

\begin{tabular}{|lcc|}
\hline & Institutions & Enrollment \\
\hline Council of Rectors Universities & 25 & 243,593 \\
Private Universities & 38 & 125,740 \\
Professional institutes & 51 & 91,153 \\
Technical Training Centers & 115 & 61,123 \\
\hline Total & 229 & 521,609 \\
\hline
\end{tabular}

Tertiary institutions are subjected to a statuary regime according to which they are located in one out of four categories, full autonomy, accredited, examined and supervised. Institutions with full autonomy have substantial freedom to plan and organize programs, designate personnel and administer the budget. The 25 traditional council of rectors universities were declared autonomous by definition. Chile has been a regional forerunner in quality assurance of tertiary education institutions and their course programs. Since 1999, provisionary national accreditation commissions have set standards and granted formal recognition to programs at the graduate and undergraduate level based on self-assessments and external peer-review processes.

To administer admissions, traditional universities set up, more than 30 years ago, the Academic Aptitude Test (PAA) comprising skills centered exams on math and language and more specific knowledge centered tests on various subjects. The PAA is designed and scored in accordance with international assessment standards. Access to traditional universities is highly competitive, with a few institutions concentrating most of the applicants.

\section{Levels and mechanisms of funding}

Chile allocates a total of 2.2 percent of GDP to tertiary education, which is the highest percentage in the Latin American region (Graph 1). Due to the aforementioned policy of cost-recovery, most resources come from private sources. This reflects high private rates of return for tertiary graduates in the labor market and a political decision to target public resources to basic education and other social priorities. 
Graph 1. Investments in higher education in percentage of GDP (2001)

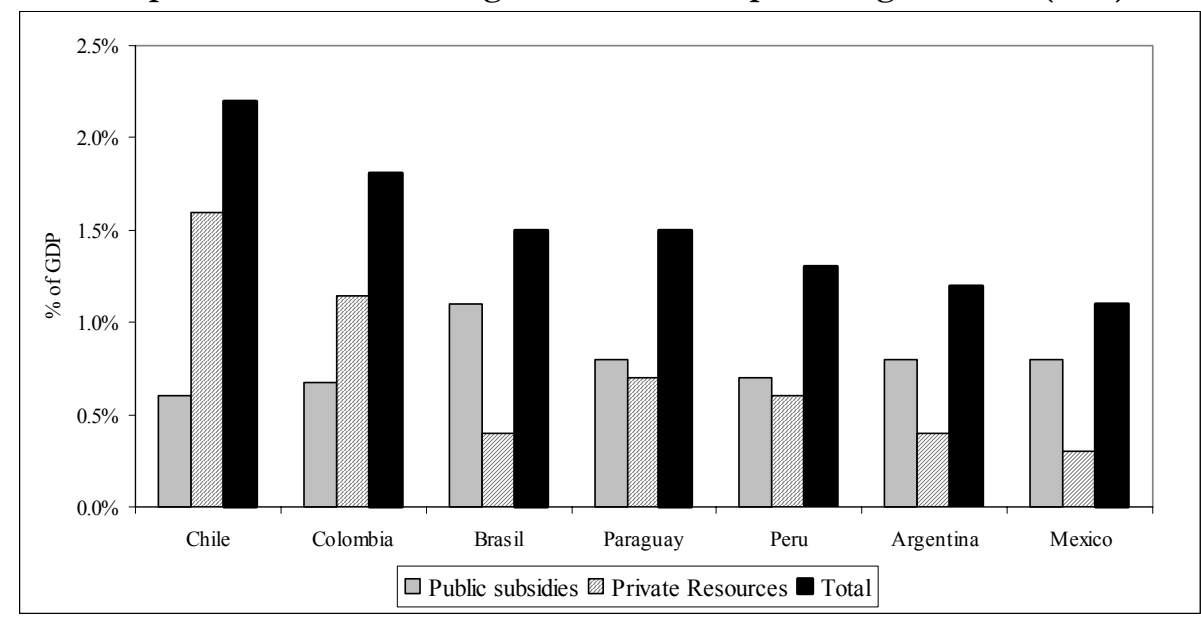

Source: OECD (2002a), World Bank (2002d) and World Bank (2002b and 2003)

Public sector funding of tertiary education comprises only 0.6 percent of GDP. This translates into one of the lowest public expenditure per tertiary student in Latin America. Moreover, spending on tertiary education is well balanced against the primary and secondary level. Primary education is currently averaging about 64 percent of annual funds allocated to education, secondary 20 percent and higher education only 16 percent (MINEDUC 2004).

Decreto Fuerza de Ley no. 4 from 1981 regulates public financing of Chilean tertiary education. Funding is allocated through four mechanisms: (i) direct public support (AFD) to the 25 traditional public and private universities; (ii) indirect public support (AFI) of public and private institutions linked to a best-student formula; (iii) funding for institutional development and quality improvement; and (iv) student financial assistance in the form of scholarships and a loan system for students enrolled in traditional universities based on an income contingent repayment scheme ${ }^{2}$.

Graph 2 shows the evolution and composition of public expenditures in tertiary education. Public expenditures for tertiary education more than doubled in real terms between 1980 and 2003. Notably, public subsidies for student financial support, direct public support (AFD) and funds for institutional quality improvement projects increased (MECESUP). Meanwhile, indirect public support (AFI) has remained stable. In 1990, AFI represented 18 percent of total public expenditures on tertiary education; in 2003, it was reduced to 7 percent.

\footnotetext{
${ }^{2}$ A project law is currently under review in the Chilean legislature, which would open up financial assistance to students attending other tertiary institutions than the traditional 25 universities.
} 
Graph 2. Public subsidies for tertiary education in Chile, 1990-2003

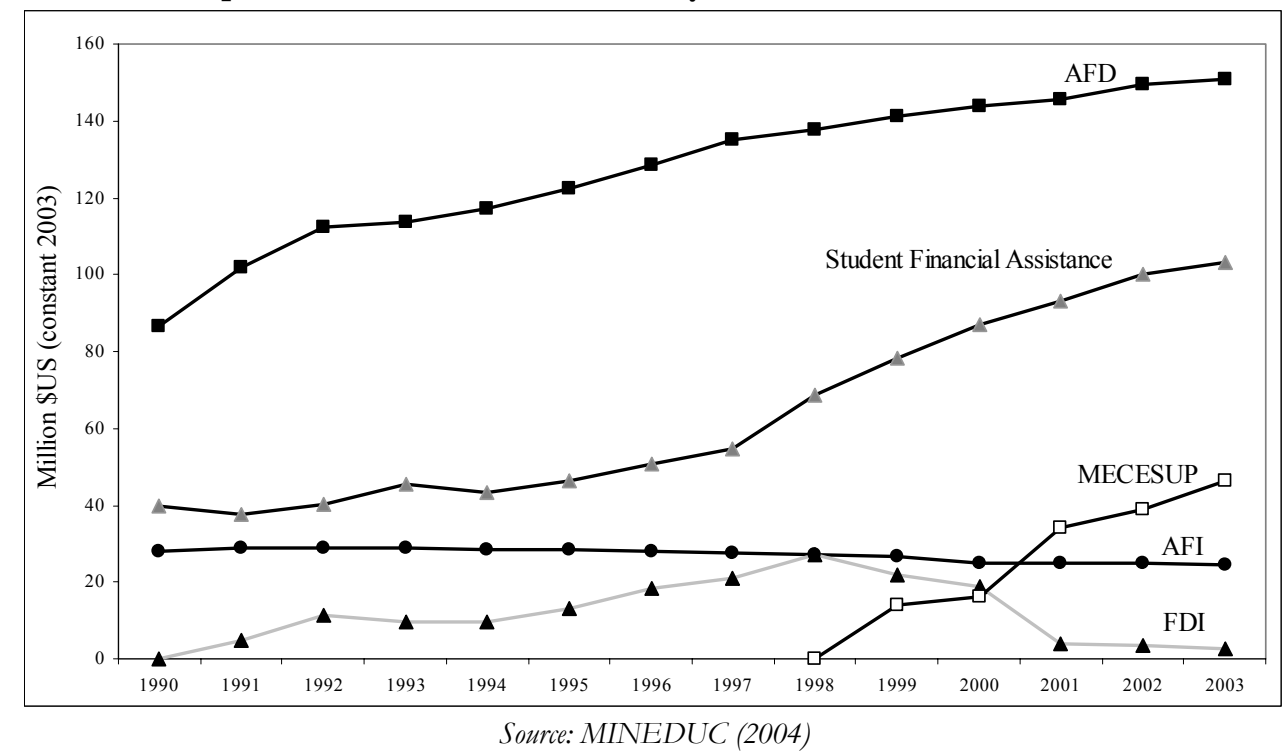

\section{Direct public support}

One of the most contentious issues regarding tertiary education in Chile is the direct financial support given to the 16 public and 9 private universities that existed before tertiary education was reformed in the early 1980s. AFD comprises about 50 percent of total public spending on tertiary education. Yet, Chile's 38 non-traditional private universities, 51 professional institutes and 115 technical training centers have no access to AFD.

95 percent of AFD is allocated to universities based on historical precedence and a process of political negotiation without systematic reference to obtained results. This allocation process maintains a highly uneven distribution of AFD funds between traditional institutions. As revealed in Graph 3, per student AFD funds vary from more than 1,400 USD per student for the University of Talca to about 150 USD per student for the Catholic University of Temuco.

Graph 3. Direct public support per student and distribution of results-based funding, 2003

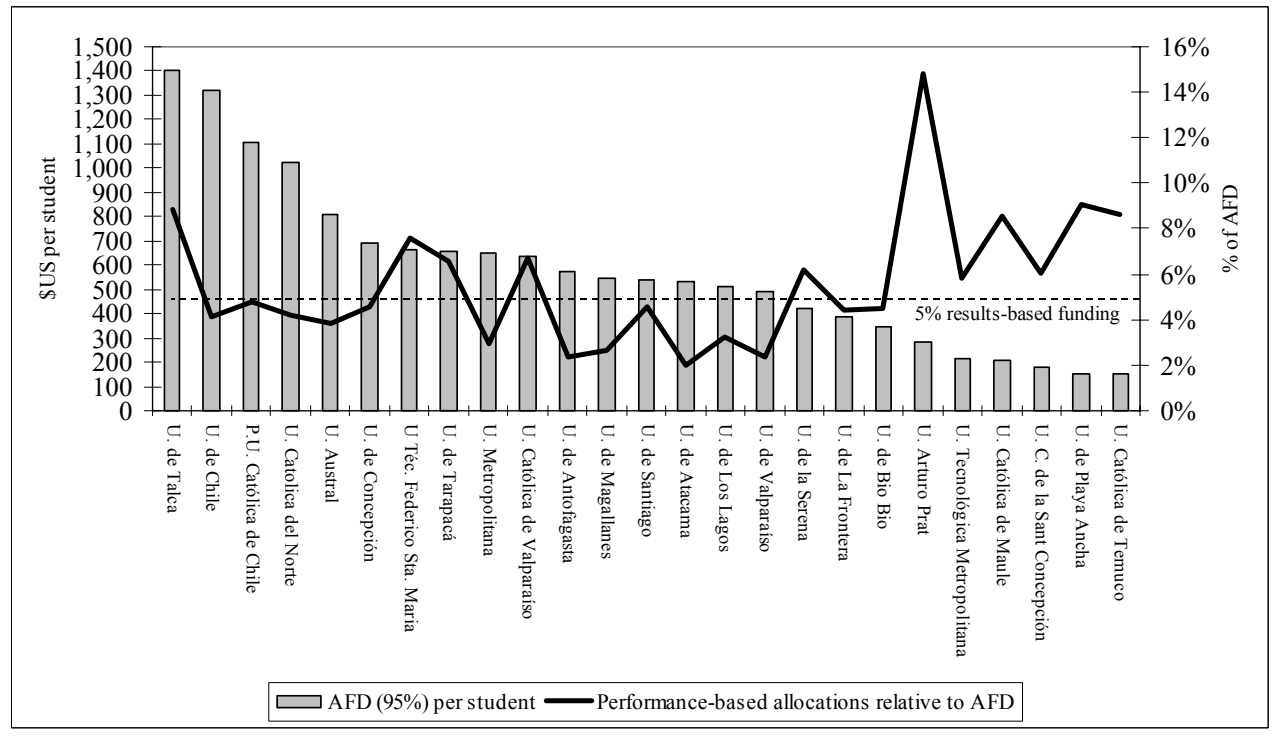

Source: Universidad de la Frontera (2004) 
Five percent of AFD is allocated to universities based on input, process and output criteria. These funds are allocated according to the relative scoring of each university on five weighted indicators: (i) critical mass obtained in each career measured by the number of undergraduate enrollees per program; (ii) internal efficiency measured by student-teacher ratios; (iii) quality measured by the number of faculty holding advanced degrees; (iv) scientific quality measured by the number of research projects per full time equivalent scholar; and (v) scientific production measured by the number of publications per researcher. High weights are placed on quality and scientific activities (84 percent) and low weights are given to efficiency and, particularly, enrollees per program.

Graph 3 reveals that performance funding does not mirror the distribution of AFD. Institutions that receive the least funding per student are all well above the default five percent results-based funding. In absolute terms University of Arturo Prat and Austral University, for example, obtained almost the same amount of performance funding in 2003, while total AFD funding per student was almost three times higher at the Austral University.

Results-based funding provides AFD universities an incentive to perform, especially in regard to the quality of staff and scientific activity. However, due to its structure and size, the mechanism has had limited impact in the sector. Moreover, problems have been encountered in the operation of the mechanism, which reduce its positive implications on transparency in the Chilean university system. Notably, the lack of a national information system with reliable, standardized statistics and unambiguous baselines has given way to errors and inconsistencies in the reporting from universities.

A bill is currently under review in the Chilean Congress that would write national accreditation of tertiary institutions into law and mandate the establishment of a national information system for post-secondary education. As a minimum, institutions would be required to provide statistics related to students, faculty, resources, infrastructure and learning outcomes. Collected information would be validated by the Ministry of Education and published annually (MINUDUC 2003). Consultations have begun between the Ministry of Education and key universities on definitions and criteria, but a final design is yet to be agreed upon.

\section{Indirect public support}

All institutions offering tertiary learning opportunities in Chile are eligible for indirect public support. The AFI is distributed to institutions according to their ability to attract the 27,500 highest scoring students in the university admission exam (PAA). In 2003, the distribution of AFI between institutions was: 82 percent for the 25 traditional universities, 17 percent for private universities and 1 percent for IPs and CFTs. 
Graph 4. Relationship between the highest PAA achievers and student economic background (2000)

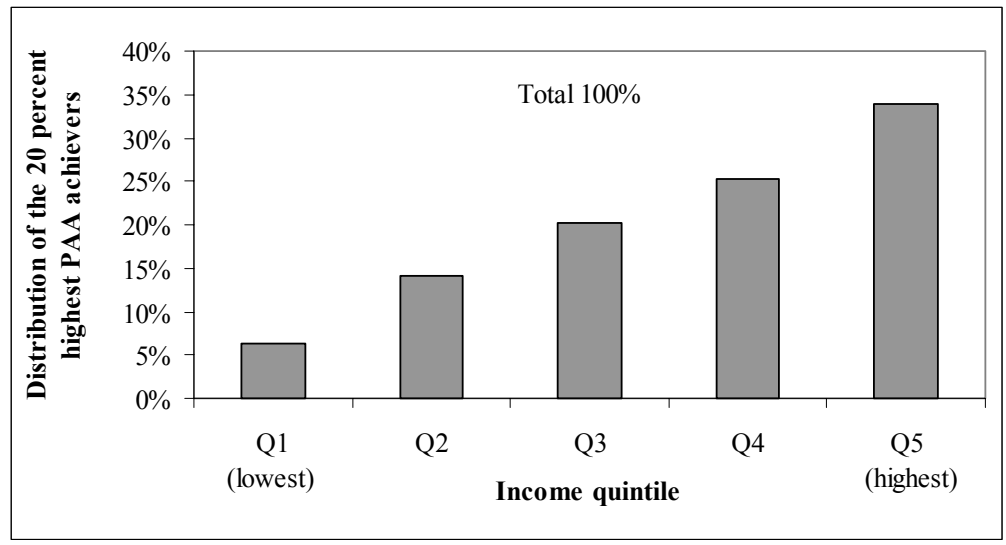

Source: Larrañaga (2001)

Indirect public funding has been successful in providing tertiary institutions - public and private - a strong incentive to respond to student needs and provide learning opportunities of high quality and relevance. As such, the AFI has been an important example of performance funding in Chilean tertiary education. Nonetheless, potential exists for improving the mechanism, particularly in regard to equity. As Graph 4 shows, PAA achievement - and hence AFI allocations - is closely linked to the ability to pay for quality basic education (Bernasconi and Rojas 2004). An alternative approach to AFI would be to tie the capitation grant to the best students from the lowest three income quintiles.

\section{Funds for institutional development}

In 1998 a decision was taken to gradually phase out the Institutional Development Fund due to criticism that political criteria dominated the allocation of funds. These shortcomings were challenged by the creation of a competitive fund for quality improvement (MECESUP) under which all tertiary institutions are eligible for support.

Designed to accelerate processes of institutional modernization, the MECESUP fund supports projects developed and proposed by tertiary institutions. Committees of peers review and select proposals according to transparent procedures and criteria. Thus far, supported areas include: (i) technical training programs; (ii) undergraduate programs in the hard sciences; (iii) graduate programs in all areas; and (iv) curricula redesign (World Bank 1998).

\section{Setting the stage for reform}

With only five percent of AFD allocated on a true performance basis, significant potential exists for increasing transparency and tying incentives to key sector priorities by rescaling and reforming existing public funding structures. Despite good intentions and a decade long debate, no action has so far been taken to supplement demand side financing with changes to the public funding regime for tertiary education established in the early 1980s. This may be for good reason. Results-based funding systems are difficult to design and may be met with considerable resistance from key stakeholders. It is against this background that the following sections discuss preconditions, design options, tradeoffs and strategies to be considered when tying funding to results.

\section{FUNDING HIGHER EDUCATION INSTITUTIONS BASED ON RESULTS}

Results-based funding can be defined as the allocation of resources contingent on achieved rather than promised results. Tying funding to results departs from traditional considerations in tertiary education of line item expenditures and inflationary increases. These constitute 
input factors and disregard results, such as graduation rates, learning outcomes and the contribution of university research to society (Fielding 1999).

Performance management rests on the assumption that effective government cannot be achieved within a classic bureaucratic framework of tight regulatory control of sources and methods of production. The relationship between the government and public tertiary education institutions can be described within the context of the principal-agent model. The providers of higher education have more information about education processes than the government. The government (the principal) therefore delegates part of the decisionauthority to the institutions (the agents). However, the information asymmetries between the government and the institutions can create agency problems: institutions can exploit their information advantages to pursue other goals. These agency problems typically arise when funding is based on inputs or on historical patterns. As the government cannot observe the effort of university staff, the system may preserve inefficiencies and ineffective programs.

A way to overcome such agency problems is to redesign funding systems, so that incentives of the principal and the agents converge. This is the essence behind the idea of results-based funding. Governments should be tight on setting goals for tertiary institutions and assessing results and provide flexibility on the methods used to achieve these ends. Thus, decision makers would assume a 'stimulative and facilitative' role centered on incentive-inducedchange rather than control and prescribe actions at the decentralized level (Windham and Peng 1997).

\section{Building systems for results-based funding}

Higher education systems are of high complexity and cater to multiple objectives. Hence, building a funding system without perverse incentives or unintended consequences requires careful consideration of design options. Perfection is unlikely to be ensured in the design phase and progress is often based on trial and error during implementation.

The impact of incentive driven institutional change is contingent on the tailoring of components to fit national and systemic characteristics. Even when an administrative culture has become obsolete or dysfunctional it remains necessary to understand its institutional roots to secure durable improvements. Equally important, administrative capacity limitations and other institutional constraints must be taken into account when designing funding systems (Schiavo-Campo 1999).

Kusek and Rist (2002) propose adjusting the complexity and ambition of a results-based funding system based on a 'readiness assessment'. Performing such an assessment gives reforming agencies an understanding of what institutional capacity they do or do not have and what resource can be drawn upon to initiative reform. A 'readiness assessment' can also help to clarify where within a government reforms might begin, under the auspices of who and what demand exists for the use of collected information.

\section{Information systems}

As governments begin to address the challenges of results-based funding, they face the need to document performance with valid and reliable information. Allocating resources based on institutional performance presupposes credible and timely national and institutional statistics on a wide range of indicators. Without a good information system no basis exists for evaluating institutional performance. When reliable data are lacking, the priority must be to build a data and monitoring capability before considering the introduction of results-based funding (Schiavo-Campo 1999). 
Box 1. University Information System (SIU) in Argentina

Initiated in 1994 under the Programa de Reforma de la Educación Superior (PRES) the Argentine Government has led the design and operation of an internet-based management information and statistical data system that integrates various existing modules needed for decision-making at the ministerial and decentralized level and provides adequate data and system compatibility with statistical systems of public universities.

The SIU consists of five main software modules: (i) accounting and budget; (ii) staff management; (iii) university statistics; (iv) library management and (v) student management. All modules are merged into a single platform and are available through the Internet for all participants. Close consultation with end-users in the development phase has ensured that modules are easy-to-use and compile data of high relevance.

Source: World Bank 2004 (ICR)

Establishing structures for data collection often involves designing computer systems that standardize information and reduce the administrative burden of handling large quantities of data. Some of the elements that need to be addressed are responsibilities for data collection, reporting and evaluation of collected information. Since institutions will be funded based on collected information, systems need build in safeguards and structures for external validation of data. National auditing agencies are often well-positioned and sufficiently independent to carry out this task.

Given the complexity of getting reporting structures right it may improve changes of success if performance reporting precedes results-based funding. Requiring tertiary institutions to present periodic reports on priority indicators prior to the introduction of results-based funding familiarizes institutions with data collection and establishes a reliable baseline from which institutional performance can be assessed.

\section{Selecting indicators}

The process of identifying indicators goes to the heart of designing a results-based funding system. As pointed out by Burke (2001a) "what gets measured is often what gets valued, and what gets funded is even more prized".

Indicators are most effective when they mirror the government's strategy for change in the higher education sector. A strategy implies the movement of the sector from its current stage to a desirable but uncertain future stage. Because the sector has never been to this future position, its intended pathway involves a series of linked hypotheses. In the Chilean Science for the Knowledge Economy Project, prioritizing outcomes and making key hypotheses explicit was an important first step in selecting indicators (Box 2). Ideally, indicators should reflect the aspects of the higher education sector that, if improved, are presumed to result in the achievement of general goals such as equity, efficiency and quality (Niven 2002). 
Box 2. Theory of change: Science for the Knowledge Economy Project in Chile

The 2003 Science for the Knowledge Economy Project in Chile supports the country's transition to a knowledge-based economy by investing in the innovation system and the stock of human capital. To determine where to monitor progress, a causality tree was drawn to display how activities and goals interlink. For each arrow in the model an indicator was selected.

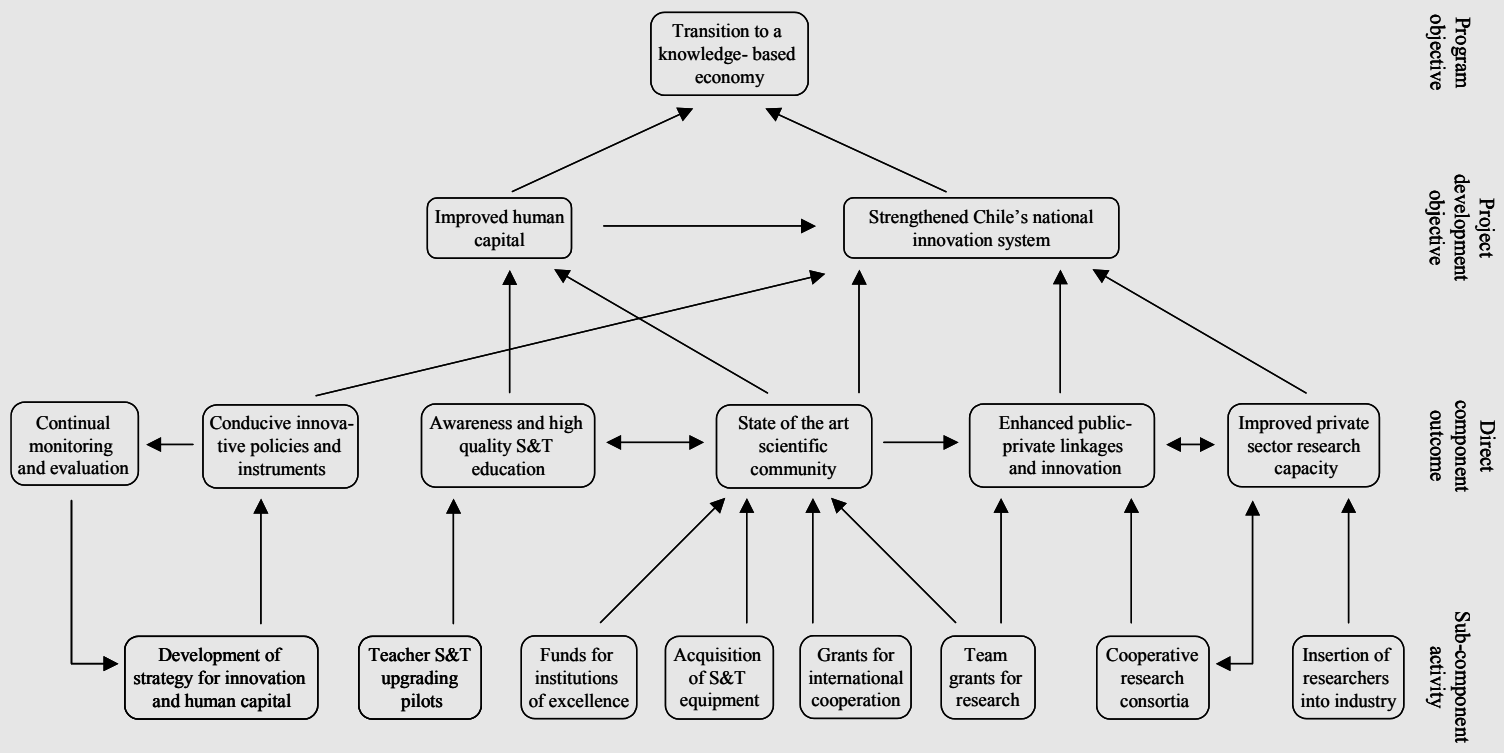

The pool of indicators provides the project management timely management information on the project's theory of change. Identified weak links permit evidence-based improvements during implementation.

Source: World Bank (2003b)

Indicators come in four types: Inputs involve the human, financial and physical resources received to support programs, activities and services, such as funding, enrollments and staffing. The performance criterion corresponding to inputs is economy, i.e., the timely acquisition of quality inputs at the lowest possible cost. Processes are the manner in which inputs are procured and the means by which results are delivered. Processes are internal to an institution and include teaching methods, the use of technology and procurement. Process indicators can be useful proxies for performance when output or outcomes cannot be defined with clarity.

Outputs reflect the quantity of products produced such as the number of graduates or the number of research articles published. The performance criterion corresponding to outputs is efficiency, i.e., maximizing the quantity of outputs in relation to a given total amount of inputs. Outcomes cover the quality and societal impact of the products produced. Outcome indicators include learning results, job placements and user satisfaction. The performance criterion corresponding to outcomes is effectiveness, i.e., maximizing outcomes in relation to the outputs produced (Schiavo-Compo 1999). 
Box 3. Indicators in US university results-based funding systems

Most states in the US use some form of performance funding or reporting based on different
indicators reflecting the preferences of policy makers in different states. Burke and Minassians
(2002b) have made a survey of the indicators used to evaluate performance in US higher
education. Some of the most commonly used indicators include:
- Administrative/academic costs/staff (input)
- Tuition and fees (input)
- Financial aid (input)
- Research sponsored by external sources (input)
- Technology/ distance learning (process)
- Student transfers (output)
- Time-to-degree (output)
- Graduation/ retention rate (output)
- Job placement (outcome)
Source: Burke et al. (2002c)

Each type of indicator reflects a tradeoff between accountability and measurability. Focusing exclusively on inputs and processes facilitates the monitoring of what and how means are used but neglects the purposes for which resources are obtained. Output indicators are relatively simple to observe and quantify but may be only vaguely associated with societal impact. Outcome indicators are generally more relevant, but also less useful for assigning responsibilities. For most purposes it is preferable to rely on a combination of indicators rather than focusing on any single measure. Yet, an abundance of data adds complexity, and risks making the performance system unwieldy and difficult to understand. Hence, most results-based funding systems attempt to strike a balance between manageability and comprehensiveness.

An indicator should preferably meet the following requirements: (i) easy to calculate; (ii) difficult to manipulate; (iii) give a reliable estimate of the institution's value added and (iv) not be subject to noise. First, it should be transparent for institutions and their employees how their performance is evaluated. If people do not know how to influence their performance, results-based funding is unlikely to work. Second, the indicator must be difficult to manipulate. For instance, test scores can be manipulated in several ways, such as teaching-to-the-exam and keeping marginal students out of the pool of tested students. Third, students learn inside and outside tertiary institutions. The indicator should measure the performance of the institution, correcting for external influences. Finally, random factors should not have a major impact on selected indicators.

Several OECD countries have experimented with establishing distinctive indicator subsystems for the funding of tertiary education. Separating e.g. indicators for teaching and research, as in the United Kingdom, may reduce complexity and allows evaluation criteria and follow-up processes to be closely tailored to each sub-system (Box 4). Nonetheless, decoupling indicator sub-systems adds to the challenge of creating incentives that support a balanced approach to institutional improvement (Jongbloed 2001). 
Box 4. Separate set of indicators for teaching and research in the UK funding system

In the United Kingdom the allocation of funding for higher education is based on two separate sets of indicators, one for teaching and one for research. Categorizing indicators cater for high specificity in the choice of indicators and allow unique follow-up procedures to be established for each set of indicators.

Teaching grant

Funding for teaching is based on several indicators such as number of students, length of courses, size of the institution, location, level of specialization and the number of disadvantaged students. The indicators have built in flexibility in order to give recognition to differing institutional circumstances.

Research grant

The calculation of funding for research is based on indicators such as the number of qualified researchers, published research documents, the number of research students and external research income. The assessment process and the allocation of funding is not solely based on the quantitative scoring on each indicator. In the so-called research assessment exercise (RAE), committees of peers evaluate the overall quality of research activities in each institution.

Source: HEFCE 2003

\section{DESIGN OPTIONS - INTERNATIONAL CASES}

Significant variety exists between countries in the methods and processes applied to select the criteria by which tertiary institutions are evaluated. Although all contain idiosyncratic details, systems can be classified into two categories: System-wide fixed set of indicators where little change is introduced over time on the criteria used to evaluate institutions and fixed-term performance contracts with explicit evaluation criteria, periodically negotiated between the supervising agency and each tertiary institution.

\section{Fixed set of indicators}

For performance systems with a fixed set of indicators, a distinction can be made between simple criteria systems where institutions are evaluated based on one or two indicators and multiple criteria systems with several indicators. France, Denmark and the Netherlands are examples of countries basing a significant part of institutional funding on a simple criteria system. Countries operating a funding system with multiple performance criteria include the United States and South Africa. In the Latin American region, Argentina is an example of a country that has - on a small scale - experimented with multiple criteria funding of higher education.

Simple criteria systems

The French tertiary education system receives about 50 percent of its funding based on a simple input formula. Funding is tied to the number of students enrolled while adjusting for variance in expenses per students in different careers. Calculated funding is allocated to institutions as a lump-sum, which provides tertiary institutions with significant budgetary autonomy. 
Box 5. Funding model for French universities

The basis for calculating funding is the number of students enrolled. The compensation that universities receive is tied to the level and type of program that the individual student is enrolled in. All programs are categorized in a grid that serves as a weighting device. Funding per student is determined using four criteria:

- Teaching staff not funded by the central government

- Compensation for non-academic staff

- Technical requirements and equipment

- Teaching facilities

Source: CDUS 2002 and CHEPS $2001 \mathrm{~b}$

The main advantage of the French system is the simplicity of the funding criterion. As pointed out, input indicators make it relatively unproblematic for decision makers to track spending and allocate funding. The drawback, however, is weak incentives for universities to provide quality education and ensure efficiency by avoiding delays in student completion.

The Danish taximeter model uses a simple output criterion to determine the level of funding for tertiary institutions. Depending on their research activities, institutions receive between 30 and 50 percent of their funding based on their educational production. For each student who passes an exam an amount of money is paid to the university. The total of these "active" students determines the available funding in a particular year. Universities do not receive compensation for students who fail their exams or do not take exams.

\section{Box 6. The Danish taximeter-model}

The Danish tertiary education funding tariff paid per passed exam, the "taximeter tariff", varies according to the field of study, and has three components:

- A tariff for the costs of education and equipment

- A tariff for joint costs (e.g. administration, buildings)

- A tariff for expenses for experimental sciences and practical training (e.g. in medicine and physics)

Source: CPH and CHEPS (2001)

The taximeter model promotes efficiency in the tertiary system by highlighting the need for students to complete their coursework and progress in the system. Hence, historically determined budgetary slack is dealt away with as institutions are only rewarded for their incremental "production". In theory, the taximeter model also facilitates student mobility between institutions since funding is tied to the student and not the institution. However, the model as implemented in Denmark is not a real voucher since students cannot use the taximeter to buy services from private providers. The risk associated with the taximeter model is the incentive of institutions to artificially increase pass rates to receive more resources. To avoid decreasing educational quality, the model depends on the existence of a strong quality assurance mechanism and deep-rooted professional standards among university staff.

The Dutch funding system allocates about 50 percent of public funding for university teaching based on an output criterion. Whereas the focus in Denmark is exams passed, the Dutch system rewards student degree completion. To avoid unintended fluctuations in funding, resources are allocated based on two-year averages of the number of graduates. An important feature of the Dutch system is that the macro-budget for the university sector is determined before deciding on the distribution of resources to individual institutions. Hence, the formula does not imperil budget stability. 
Box 7. Funding model for Dutch universities

The distribution of resources to individual institutions is constrained by a fixed macro-budget for the university sector. The allocation of the budget is based on the number of students who completed their program multiplied by the normative study duration (4.5 years) plus the number of students who drop out multiplied by an administratively set study duration of these dropouts (1.35 years). The total amount of funding is then calculated by multiplying calculated graduation numbers by a fixed reimbursement per student (i.e. 4,477 euro for Engineering students and 3,461 euro for students in other programs in 2001).

Source: CPH \& CHEPS 2001

The Dutch funding system provides a strong incentive to dismiss incapable students as soon as possible and to assist talented students in graduating without delay. The simple performance criterion makes it transparent to institutions how they will be evaluated and thereby facilitates the adoption of long-term strategies to reduce university dropouts. However, as is the case in the Danish and French tertiary funding system, the evaluation criterion does not by itself cater multiple objectives such as quality, relevance and equity.

\section{Multiple criteria systems}

The US state of Tennessee applies multiple performance criteria to about 6 percent of the core budget for higher education. The funding system consists of four standards and ten indicators, each given a certain weight. Built into the system are provisions that allow institutions to be evaluated differently based on the type and duration of their degrees. An important characteristic of the funding system is that universities are competing against their own record. Hence, a university is not advantaged by the poor performance of another institution. The system is revised every five years and each revision gives the state as well as the universities a chance to decide on new policies and changes in the nature and number of indicators (Bogue 2002).

Box 8. Performance indicators used in the Tennessee funding formula

The scorecard represents the weight assigned to each indicator and hence the relative priority given to the goal.

\begin{tabular}{|c|c|c|}
\hline Indicator & $\begin{array}{c}\text { 2-year } \\
\text { campuses }\end{array}$ & $\begin{array}{c}\text { 4-year } \\
\text { campuses }\end{array}$ \\
\hline \multicolumn{3}{|l|}{ Standard 1-Academic Testing and Program Review } \\
\hline - Foundation Testing of General Education Outcomes & 15 & 15 \\
\hline - Pilot Evaluations of Other General Education Outcome Measures & 5 & 5 \\
\hline - $\quad$ Program Accountability & & \\
\hline 1. Program Review & 5 & 10 \\
\hline 2. Program Accreditation & 10 & 15 \\
\hline 3. Major Field Testing & 15 & 15 \\
\hline \multicolumn{3}{|l|}{ Standard 2-Satisfaction Studies } \\
\hline - Student/Alumni/Employer Surveys & 10 & 10 \\
\hline - Transfer and Articulation & $\mathrm{N} / \mathrm{A}$ & 5 \\
\hline \multicolumn{3}{|l|}{ Standard 3- Planning and Collaboration } \\
\hline - Mission Distinctive Institutional Goals & 5 & 5 \\
\hline - State Strategic Plan Goals & 5 & 5 \\
\hline \multicolumn{3}{|l|}{$\begin{array}{l}\text { Standard } 4 \text { - Student Outcomes and Implementation } \\
\bullet \quad \text { Output Attainment }\end{array}$} \\
\hline 1. Retention/Persistence & 5 & 5 \\
\hline 2. Job Placement & 15 & $\mathrm{~N} / \mathrm{A}$ \\
\hline 3. Assessment Implementation & 10 & 10 \\
\hline Total Points & 100 & 100 \\
\hline
\end{tabular}

The implementation of the Tennessee model has been assured through the involvement of institutional and government officials in the funding procedure, thereby giving all levels a 
sense of ownership to the system. In the 1997-2002 cycle, campuses were for instance permitted to choose two performance indicators, one related to their own educational interests and one directed to the State's strategic goals. Yet, the system has been criticized for involving too many people and using an excessive amount of resources on calculating indicators that are of limited use in tertiary institution internal decision-making (Bogue 2002).

The Argentine resource allocation model for tertiary education is designed to close gaps between the real budget need in ideal quality and efficiency conditions and the actual budget allocated based on historical criteria. Based on three criteria, the model matches the estimated minimum necessary resources to finance the current level of scientific, academic and administrative activities.

Box 9. The Argentine AR-model

Allocation of funding through the AR-model (Asignación de Recursos) is based on the 'objective' budget. The calculation of this budget draws on the following criteria:

- Number of effective students

- Pedagogically adequate teacher per student ratios

- Teachers' salary scales

Source: World Bank (2003b)

Rather than targeting existing base funding of Argentine tertiary institutions, the model is applied to increases in public subsidies for tertiary education. Due to Argentina's economic crisis, the model currently only comprises about 4 percent of the public budget for tertiary education.

The South African funding model - applied to 89 percent of the core budget for higher education - is another example of a multi-criteria approach. Block grants for public tertiary education are divided into four categories reflecting teaching, research and specific institutional issues. The Ministry of Education publishes an annual statement, which determines how performance criteria will be calculated and weighted. This provides clarity to institutions on how they will be evaluated while ensuring a degree of flexibility despite the use of pre-selected indicators.

Box 10. Performance based grants in South Africa

The funding formula is based on four input and output weightings:

1. Teaching inputs: Total number of enrolled second year students is passed through a grid, placing enrollees into four study categories, which are weighted according to a) course material, b) course level and c) instruction-delivery mode.

2. Teaching outputs: Number of enrolled students multiplied by graduation benchmarks. Benchmarks are approved by the Minister of Education on a rolling three-year basis.

3. Research outputs: Actual totals of doctoral and post-doctoral graduates and research publication units for a specific year compared to a normative total according to national benchmarks.

4. Institutional factors: (a) grants for institutions with large proportions of disadvantaged students and (b) grants related to the size of institutions based on the number of enrolled students.

Source: Ministry of Education, South Africa (2004) and Government Gazette (2003)

An interesting feature of the South African model is the operation of a competitive fund for institutional development to supplement the multi-criteria funding system. Critics of resultsbased funding often charge correctly that removing resources from institutions with poor performance will only make improvement more difficult, if not impossible. In South Africa, under-performing institutions are not necessarily destined to declining budgets. By gaining 
access to earmarked competitive funding, these institutions have an opportunity to improve themselves by financing institutional restructuring. Another option would be to place funds not earned by poor performing institutions in escrow and releasing them when these institutions submit acceptable improvement plans for remediation (Burke 2001a).

Multiple-criteria funding can cater multiple objectives and can consequently be used as a driver for specific, high-priority tertiary education policy components. In contrast to simple indicator systems, multiple criteria make it easier for policy makers to ensure a balanced sector development and avoid unintended consequences. However, multiple criteria formulas may result in a complex and opaque funding system. When providing incentives to the decentralized level, simplicity may sometimes provide the greatest benefits.

\section{Performance contracts}

Results-based funding based on performance contracts is a flexible design where evaluation criteria are negotiated between the supervising agency and each tertiary institution. Performance contracts are institution specific rather than system-wide in their content and application. They typically cover a period of 3-4 years.

Performance contracts have been used in France since 1989 - in addition to the aforementioned simple input formula - where government adopted a system of university funding through performance-centered budget dialogues. These dialogues lead to four-year contracts between the government and universities.

Universities are asked to provide a self-assessment, and to present their plans for the next four years. These plans form the basis for discussions with the Ministry of Education. In this dialogue, goals and evaluation criteria are identified and agreement is reached on how public funding will be tied to results. The contracts are not legally binding documents but "reciprocal commitments", which serve as a reference to make decisions within the university system. In 2000, 188 institutions representing 75 percent of total tertiary enrollment were involved in contract funding (CHEPS 2001b).

\section{Box 11. Results-based contracts in French tertiary education}

Results-based contracts in French tertiary education consist of a base and a strategic part. The base part targets long-term investments in buildings, equipment and facilities. The strategic part is an agreement on the financing of priority projects including new technology, student life and libraries.

Projects suggested under the contractual budget have to be new initiatives that cannot be financed through the recurrent budget. To avoid that contractual budgets are used to fill gaps in university budgets, objectives and indicators are made very clear and the contracts tailored to each institution. The state thereby hopes to stimulate the link between objectives and resources and provide an incentive for universities to achieve agreed results.

Source: CDUS (2002)

The contractual budget comprises on average about a third of total public subsidies for tertiary education. The impact on decision-making processes has been substantial. Notably, the contract regime has prompted the development of tools for expenditure analysis and management information systems to support institutional improvement processes and planning (Musselin and Mignot-Gerad 2002).

Performance contracts have been met with some resistance from within French universities. In part, this reflects a lack of performance dialogue with heads of faculties and departments that are responsible for delivering agreed results. Performance contracts are agreements between university presidents and the Ministry of Education (Musselin 2002). As Burke and Minassians (2002a) point out - drawing on experience from the United States - a key 
problem is that performance criteria tend to become increasingly invisible on campuses below the level of vice presidents, because of the failure to extend performance funding and reporting to internal academic units.

Finland has prioritized consultation in the contract negotiation phase through an intensive budget dialogue involving lower management levels and regular reporting between universities and the Ministry of Education during the contract period.

Prior to performance contract negotiations, universities send in proposals including an activity and a finance plan for a three-year period. This launches a process of consultation where the Ministry of Education and universities identify targets and evaluation criteria. Ministry officials and university staff, inter alia, interact in unofficial seminars and meetings in order to take account of institutional and disciplinary views and ensure transparency and predictability in the negotiation process (Hölttä and Rekilä 2003).

The Finnish performance contracts include both general goals for the tertiary education system such as quality, impact of education and total number of offered degrees as well as specific goals for the individual institution.

\section{Box 12. Finnish performance contracting}

Finnish performance contracts are made up of three parts: core funding, performance funding and funding for specific initiatives. Deliverables for all three types of funding are agreed in the contract. The core funding remains stable during the tree-year contract period, whereas performance funding (approximately 3-5 percent of operational expenditure) is tied to results on a number of agreed indicators. Examples of indicators include:

- Funding for research from external sources

- Assessed learning achievement

- Provision of adult education

- Graduation time

- Participation in international cooperation

To calculate the amount of performance funding, target figures are multiplied by a field-specific cost factor, which is also agreed for the three-year contract period.

Source: Hölttä and Rekilä 2003

Funding based on performance contracts gives wide room for political maneuverability and prioritization of high profile government policy. While this impairs institutional planning beyond the contract period, it caters for political necessities and ensures system endurance. Performance contracts offer a significant degree of flexibility to take account of idiosyncratic characteristics and needs when tertiary institutions are few and differences between them are large. If the tertiary education landscape is fairly homogenous and composed of a high number of providers, contracts may not be efficient.

A notable feature of performance contracts is the high demand they place on the capacity of supervisory authorities to engage in an evidence-based dialogue with institutions. Without a strong counterpart, information asymmetries may lead to under-performance, as institutions are able to press for undemanding targets. Hence, if sufficient steering capacity at the central level does not exist, funding tied to a fixed set of system-wide criteria is likely to be more effective than contracts in driving institutional improvement.

\section{REWARDING INSTITUTIONS BASED ON PERFORMANCE}

In addition to agreeing on the criteria that will be used to assess institutional performance, a need exists to decide how and what proportion of resources will be tied to results. In considering how institutions should be rewarded or penalized based on their performance, 
Burke and Minassians (2002a) have introduced a useful distinction between performance funding and performance informed budgeting.

Performance funding ties public funding directly and tightly to the performance of tertiary institutions on one or more predefined indicators. The tie is automatic and formula-based. If a university achieves a set target on an indicator, it receives a specific amount of performance funding. By contrast, performance informed budgeting allows policy makers and administrators to consider institutional achievement on performance indicators as a guiding factor in determining resource allocations. The link in performance informed budgeting is loose and discretionary (Burke and Minassians 2002a).

Performance funding and performance informed budgeting each has strengths and weaknesses. Performance funding offers a high degree of predictability and provides high power incentives for institutions to perform. Funded institutions know precisely how their performance will be evaluated and which aspects of their institution need to be strengthened in order to obtain additional resources. Hence, performance funding allows long-time planning and creates a stable environment in which institutions can improve. Performance informed budgeting, on the other hand, provides weaker incentives to perform since achieved results are only considered indirectly in the resource allocation process.

Box 13. Performance funding and performance budgeting in US states

In 2001 there was a total of 37 US states with either performance funding (19), performance informed budgeting (27) or a mixture of the two models (9).

Performance funding has proven relatively easy to introduce but often difficult to implement and maintain. Many states have experimented with performance funding, but in recent years the trend has been towards performance informed budgeting, which has proven to be more flexible and sustainable.

In many cases performance informed budgeting models began as performance funding initiatives. Missouri, for example, introduced a performance funding system based on indicators. The funding model turned out to be too costly and the State ultimately decided to use indicators merely as an input to budgeting and the earmarking of funds.

Nine US states have chosen a dual system with elements of both performance funding and performance budgeting, allowing the benefits of each approach to be combined.

Source: Burke (2002b)

The profiled strengths and weaknesses are reversed when considering system endurance. Performance funding does not allow discretionary policy decisions to be made in light of budget constraints or political necessities. With budget shortfall and high institutional performance, the system may not endure as decision makers would not be in a position to reward institutions according to the agreed formula. By contrast, performance informed budgeting provides more flexibility to control aggregate spending and maintain the funding system despite changes in economic or political circumstances. A loose tie between funding and performance appropriately reflects that budgeting is inherently political, and legislators are often reluctant to cede their budgetary discretion to a "rational" performance-based budgeting system (Moynihan 2003).

The described funding types are not mutually exclusive. Designing a system with elements of both performance funding and performance budgeting allows the tertiary education system to achieve the benefits and counter some of the problems of each approach. In the United Kingdom, for example, teaching and research are evaluated based on a fixed set of indicators. Yet, the process of determining the scoring on each indicator - and in turn 
funding - is not entirely quantitative and mechanistic. Qualitative peer review processes allow issues such as extra cost of providing for certain types of students and the quality of research to be factored in when assigning resources to tertiary institutions (HEFCE 2003).

\section{Tying government subsidies to indicators}

There are generally three methods by which performance funding can be determined based on predefined indicators. First, institutions can be awarded a predetermined amount of funding for each unit delivered. Examples of production units include enrollees and tertiary graduates. Production unit allocations can be designed to compensate for differences in the cost structure of tertiary programs. However, unit-cost mechanisms are rarely able to take account of changes in the marginal cost that accompany fluctuations in enrollment (Brown and Camber 2002). Second, funding can be tied to the degree an institution reaches agreed targets. Full goal achievement triggers a predetermined ceiling amount whereas results below the targets are rewarded with a fraction of this amount. Tying funding to target achievement rely on a strong capacity at the level of the Ministry of Education to set ambitious, but realistic targets. Finally, funding can be allocated according to inter-institutional benchmarking where institutions are funded according to their relative scoring on selected indicators. On each indicator, the institution that performs the best determines the target. A predetermined cap amount is tied to the best achievement, and a fraction of this amount will be allocated to institutions according to their relative goal attainment.

Per production unit and degree of target achievement performance allocations install strong incentives for performance that are easy to communicate to internal stakeholders. However, they presuppose reliable and timely baseline data. Funding tied to inter-institutional benchmarking creates an element of competition between public institutions and introduces flexibility into institutional funding systems. Nonetheless, benchmarking does not allow for institution specific indicators and makes it less transparent for institutions what will trigger additional resources.

\section{Weighing indicators}

Results can be ranked by assigning weights to indicators. This allows supervising authorities to promote specific institutional objectives while placing less emphasis on others. Hence, weights offer flexibility since they permit political priorities to be reflected in the allocation of funding. Weights may also accommodate for changing priorities without opening discussions on evaluation criteria.

While being politically attractive, weights risk undermining the importance of certain goals as institutions focus their efforts on indicators with greater weights (Serban 1998). Moreover, weights may disproportionately favor institutions that have already achieved high performance on some indicators. Assigning equal, or almost equal, weights to all indicators is likely to be less contentious, but may trigger frequent changes to the battery of indicators.

\section{Levels of results-based funding}

Allocating all resources on a performance basis may lead to significant variation in institutional funding from one year to another. Budget instability is likely to work to the detriment of improvement processes, as tertiary institutions would need to make dramatic adjustments to fixed and variable cost structures in order to match the level of funding each year. Adjustments imply the hiring of faculty and staff in years where performance is positive, and massive layoffs in years when performance does not meet expectations. To avoid such fluctuations, most countries limit performance funding to a predefined fraction of public subsidies for tertiary education. This need not reduce incentives to perform, as the 
- in most cases - discretionary nature of results-based funding gives tertiary institutions an incentive to pursue it (Brown and Gamber 2002).

Concern about budget stability often leads government to tie performance funding to additional money, that is, funding that comes on top of the base budget tertiary institutions would receive in any given year. As demonstrated by the aforementioned move to introduce performance funding in Argentina, this approach is vulnerable to budget cuts, as alternative funding programs are often the first to be suspended. Introducing results-based funding as a fraction of institutional base budgets likely increases the impact on institutional performance and reduces the system's vulnerability to budget cuts. Nonetheless, performance driven cuts to base budgets - as pointed out - may require painful adjustments to cost structures from year to year. Also, this approach may be met with strong resistance in the design and implementation phase, as more stakeholders stand to lose from low institutional performance (Serban 1998).

\section{IMPLEMENTATION}

Implementing a performance-based funding system goes beyond technicalities. Even a carefully tailored design may fail if it does not rest on some degree of support from key stakeholders. Tertiary institutions are generally populated with well-articulated individuals, some of which stand to lose from changes in funding structures. Hence, developing an implementation strategy with explicit assumptions and contingency plans increases the likelihood of success.

Three methods exist for initiating results-based funding: (a) legislation mandates the system and specifies evaluation criteria; (b) legislation mandates the system and establishes the framework for decision-makers and institutional management to agree on indicators and reward mechanisms; and (c) supervisory authorities in collaboration with institutional management voluntarily agree on and adopt a new results-based funding system (Burke and Minassians 2002a).

Mandated systems provide clarity and commit policy makers to systemic changes. While mandated systems institute a system on paper, they risk undermining program sustainability if they are imposed from above and ignore the importance on consulting stakeholders. No consultation generally means no consent and ownership at the decentralized level to resultsbased funding. 
Box 14. UNAM's failed move to raise tuition

A 10-month-long student strike during 1999 and 2000 over a move to increase tuition at Mexico's largest university, Universidad Nacional Autónoma de México (UNAM), illustrates the complexity of implementing finance reforms.

In March 1999, the University's governing council passed a general bylaw on payments, thereby breaking a tradition of virtually no tuition for the institution's student body of roughly 300,000. By April, UNAM found itself paralyzed by a student strike, and some strikes in solidarity had spread to other tertiary institutions in Mexico.

Students denounced the tuition effort as authoritarian and attacked the approval process as lacking in transparency. Of particular controversy was the fact that the Council had met off campus for the first time ever when making the decision. Of the 35 members not present at the meeting, 28 were student representatives. In the end, the university administration gave in to student demands by making new tuition voluntary.

Although less contentious than cost recovery, the painful and lengthy confrontation at UNAM illustrates a need to consider the political economy when tying funding to performance. Legitimate decision-making implies a complex dynamic of university politics in which a broad range of interests and academic perspectives are openly expressed and taken into account.

Source: Levy et al. (1999) and Ordorika (2002)

Resistance can be expected from groups that stand to lose from reform. Notably, the success of changes to the financing of higher education depends on the incentive system and the way incentives are shared. Financing reforms are generally most successful when members of the dominant, or powerful group are convinced that they will benefit and those who are adversely affected are less influential (Varghese 2004).

Resistance may also arise from those that will be better off as a result of the reform. Perhaps this group is not well informed, or dislikes change and uncertainties. Thus, information and actions to demystifying suggested changes to institutional funding is important in the preparatory phase. One strategy to build consensus is to offer financial compensation. When groups that tend to lose from the reform receive some form of compensation, they might be willing to give up their resistance. This strategy is often used in practice, but naturally lowers the efficiency gains from the reform. Another approach to garner institutional support is to introduce performance funding, at least for the first few years, as additional funding for tertiary education.

Prior to nation-wide introduction, results-based funding models can often be improved through small-scale experiments. Pilots and phased implementation create opportunities for further refinement and adaptation of the mechanism and scaling up based on evidence and lessons learned. Specialized training in data collection, reporting and analysis may be needed in tertiary institutions and ministries prior to implementation. Also, management structures may need to be updated to operate the system. Careful specification and a common understanding of all elements of the system are key to success. Clearly defined responsibilities make it apparent to everyone involved what, when, how and by whom performance data will be collected and reported to supervisory authorities. 


\section{CONCLUSION - OPTIONS FOR CHILE}

The critical importance of tertiary education in a knowledge-based society suggests a need for strengthening linkages between the funding of institutions and achieved results in Chilean tertiary education. First, results-based funding would provide Chilean policymakers with an opportunity to balance increased accountability with institutional improvement. Second, funding by results may increase the efficiency and transparency of the market for tertiary education in Chile. Finally, tying incentives to political priorities would serve as an effective driver for addressing key sector issues.

The educational sector is no stranger to transparency and evaluation. Chile has a long tradition of openness about learning outcomes and responsiveness to comparative evidence from abroad. In tertiary education, a mechanism was recently established to fill information gaps on the labor market outcomes of graduates. In addition, accreditation processes have provided tertiary institutions with important diagnostic tools and a small fraction of direct public support (AFD) is tied to performance. Hence, Chile is in a favorable position to take the next step toward funding by results.

The current concentration of public subsidies and student loans in traditional universities can be understood in historical terms. Yet, it is important to evolve the funding system toward a system that relates public subsidies more closely with results. When considering design options, Chile would be able to draw on a rich base of international experiences and good practices in results-based funding.

One of the main prerequisites for funding by results is the existence of a system for collecting and reporting performance information. Although universities and the Ministry of Education collect some statistics, significant effort would need to go into building necessary information structures with build-in verification procedures and safeguards. The proposed law on accreditation would provide a clear mandate to commence this task.

A simple taximeter design does not suffice. Chile is faced with several sector issues that concern more than efficiency and dropouts. Multifaceted sector issues require complex responses, which should be mirrored by the incentive structure established by the funding system. Multiple-criteria funding can be used to drive the implementation of reforms, e.g. pertaining to equity and curricula reform.

Any funding methodology will need to recognize that there are major differences between Chilean tertiary institutions in terms of size, offered degrees and cost structure. The University of Chile, for example, has the responsibility for the National Seismology Center. The financing of such a center should not be based on the educational performance of the Department of Geology.

Given the heterogenic nature of Chilean tertiary education, a contract design may be most effective and manageable. Performance contracts, with periodic adjustments, can be tailored closely to institutional specifics and linked to sector priorities. However, contracts would require capacity building in the Ministry of Education - beyond the current capacity in the Higher Education Division - for analyzing data and effectively negotiating evaluation criteria and targets.

Results-based funding may strike hard in institutions far from the frontier of knowledge. Maintaining a competitive fund for tertiary education with rigorous review processes would allow underperforming institutions to improve themselves by obtaining time-limited funding for institutional restructuring. 
To build consensus for reform, performance funding could initially have an element of additional funding for tertiary education. However, a lasting impact in the sector requires that results-based funding be applied to a significant proportion of the base budget. Hence, the success of performance funding in Chilean tertiary education is closely tied to a reform of direct public support (AFD).

Adopting a model of performance funding - rather than performance informed budgeting would mark an important change in the funding for tertiary education in Chile. Tying funding directly and tightly to performance provides transparency and predictability. Reaching agreement beforehand on a fixed macro-budget would ensure stability in the budget for tertiary education.

Changes in the funding of the traditional universities would likely meet resistance from both political interests and students. Therefore, a pragmatic approach, building the case for legislative action slowly and on the basis of results rather than more radical immediate reforms, may be the only way to ensure a real impact in the university system.

Piloting agreed designs in a few tertiary institutions with reliable statistics would allow the system to be refined and improved before being applied to the entire sector. Particularly, it could be tested how best to encourage institutions to establish internal structures of accountability. That way agreed performance criteria and targets would be visible and have an impact below the level of top university management. 


\section{REFERENCES}

Becerra, Marcelo; Oscar Cetrangolo; Javier Curcio and Juan Pablo Jiménez (2003). Public Expenditure on University in Argentina The World Bank, Argentina country office

Bernasconi, Andrés and Fernando Rojas (2004). Informe Sobre La Educación Superior En Chile: 1980-2003, Universidad de Talca and Universidad Andrés Bello

Bogue, E. Grady (2002). Twenty Years of Performance Funding in Tennessee : A Case Study of Policy Intent and Effectiveness, Burke, Joseph and al., Albany, New York: The Rockefeller Institute Press

Burke, Joseph C. (2001a). Paying for Performance in Public Higher Education, In Dall Forsythe (ed), Quicker, Better, Cheaper? Managing Performance in American Government, Albany: The Nelson A. Rockefeller Institute of Government

Burke, Joseph C. and Henrik Minassians (2002a). Performance Reporting: The Preferred "No Cost" Accountability Program - The Sixth Annual Report, Albany: The Nelson A. Rockefeller Institute of Government

Burke, Joseph C. and al (2002b). Funding Public Colleges and Universities for Performance: Popularity, problems and prospects, Albany, New York: The Rockefeller Institute Press

Burke, Joseph C.; Henrik Minassians and Po Yang (2002c). State Performance Reporting Indicators: What Do They Indicate? Planning for Higher Education. 31(1): 15-29

Canton, E. (2003). Power of incentives in public organizations when employees are intrinsically motivated, Prague, August 2003: Paper presented at the 59th Congress of the International Institute of Public Finance.

CDUS (2002). Financement de l'enseignement superieur, Paris: Conference des Doyens de Sciences

CHEPS (2001a). Public funding of higher education: A comparative study of funding mechanisms in ten coutries, Enschede: Center for Higher Education Studies

CHEPS (2001b). Higher education in France. The Hague: CHEPS, Country report. Nr 29

CPB \& CHEPS (2001). Higher Education Reform: Getting the Incentives Right, The Netherlands

Forskningsministeriet (1998). Universitets- og forskningspolitisk redegoerelse, Copenhagen: Ministry of Science and Technology

Fielding Smith, James (1999). The Benefits and Threats of PBB: An Assessment of Modern Reform, Public Budgeting and Finance; 19 (3), pp. 3-15

Giugale, Marcelo M.; Olivier Lafourcade and Connie Luff (2002). Colombia, the economic foundation of peace. The World Bank, Washington D.C.

Government Gazette (2003). Government Funding of Public Higher Education, August 2003

Hatry. H. (1999). Performance Measurement: Getting Results, Washington D.C.: The Urban Institute

HEFCE (2003). Funding Higher Education in England - How HEFCE Allocates its Funds, London: Higher Education Funding Council for England

Holm-Nielsen. Lauritz B.; Kristian Thorn; Jose Joaquin Brunner and Jorge Balan (2004). Regional and International Challenges to Higher Education in Latin America, World Bank, Washington D.C.

Holtta, Seppo and Eila Rekila (2003). Ministerial Steering and Institutional Responses: Recent Developments of the Finnish Higher Education System, University of Tampere and Universtiy of Vaasa, Finland

Jongbloed, B.W.A. and J.J. Vossensteyn (2001). Keeping up performances: An International Survey of Performance-based Funding in Higher Education, Journal of Higher Education Policy and Management, Vol. 23, No. 2, pp. 127145

Kusek, Jody Zall and Ray C. Rist (2002). Building Results-based Monitoring and Evaluation Systems: Assessing Developing Countries Readiness, Zeitschrift fuer Evaluation, No. 1, pp. 151-158

Larrañaga, Osvaldo (2001). Elementos para una reforma del sistema de crédito estudiantil en Chile, Departamento de Economía: Universidad de Chile

Levy, Daniel C. and Jorge Arenas (1999). The Tuition Battle at Mexico's National University, International Higher Education, Summer

Martin, J.C. and A.Verdaguer (1999). Funding and Recognition, A Comparative Study. Ministerie van OCW

Ministry of Education, South Africa (2003). A new framework : how Government grants are allocated to public higher education institutions

Ministry of Science, Technology and Innovation (2003). Danish universities in transition, Background report to the OECD examiners panel

MINUDUC (2003). Proyecto de Ley: Segundo informe de la colisión de educación, cultura, deportes y recreación, que establece un sistema nacional de aseguramiento de la calidad de la educación superior, Santiago: Ministerio de Educación

MINUDUC (2004). Chile: Compendio de Educación Superior, Santiago: Ministerio de Educación

Moynihan, Donald P. (2003). Performance-based Budgeting: Beyond Rhetoric, The World Bank: PREM notes, February, No. 78

Musselin, C. (1996). State/ university relations and how to change them: The case of France and Germany, Presentation at Open University in London (May 15, 1996) 
Musselin, C. and S. Mignot-Gérard (2002). The recent evolutions of French universities. Published in: A. Amarai, G.A. Jones, and B. Karseth (Eds.), Governing Higher Education: National Perspectives on Institutional Governance, Kluwer Academic Publishers

Niven, Paul R. (2002). Balanced Scorecard Step by Step: Maximizing Performance and Maintaining Results, New York: Wiley

OECD (2002). Education at a Glance - OECD Indicators 2002, Paris: Organization for Economic Co-operation and Development

Ordorika, Imanol (2002). The Political Nature of the Universidad Nacional Autónoma de México, International Higher Education, Winter

Robert S. Kaplan and David P. Norton (2001). The Strategy Focused Organization - How Balanced Scorecard Companies Thrive in the New Business Environment, Boston, Massachusetts: Harvard Business School Press

Serban, Andrea M. (1998). Performance Funding Criteria, Levels, and Methods, In: Burke, Joseph C. and Andreea M. Serban. Performance Funding for Public Higher Education: Fad or Trend?, San Francisco: Jossey-Bass Publishers

Schiavo-Campo, Salvatore (1999). Performance Measurement in Public Administration, Asian Journal of Political Science, December 1999

Undervisningsministeriet (1998). Rapport om taxameterstyring, Copenhagen: Ministry of Education

Universidad de la Frontera (2004). Aporte Fiscal Directo, Temuco, Agosto de 2003

Varghese, N.V. (2004). Incentives and Institutional Changes in Higher Education, Higher Education Management and Policy, Volume 16, No 1, pp. 27-39

Windham, D.M. and Peng, W. (1997). Incentive Concepts and Macro-economic Planning, in F.N. Kemmerer and D.M. Windham (eds.), Incentive Analysis and Individual Decision Making in the Planning of Education, IIEP, Paris, pp. $1-16$

The World Bank (1994). Higher Education: The Lessons of Experience, Washington D.C.: The World Bank

The World Bank (1998). Higher Education Improvement Project - Project Appraisal Document, Washington D.C.: The World Bank

The World Bank (2002) World Development Indicators 2002, Washington D.C.: The World Bank

The World Bank (2003b). Chile: Science for the Knowledge Economy Project, Project appraisal document, Washington D.C.: The World Bank

The World Bank (2004). Argentina: Higher Education Reform Project, Implementation Completion Report, Washington D.C.: The World Bank 